\title{
Quality of chronic disease care for older people in care homes and the community in a primary care pay for performance system: retrospective study
}

\author{
Sunil M Shah, senior lecturer in public health, lain M Carey, research fellow, Tess Harris, general practitioner \\ and senior lecturer in primary care, Stephen DeWilde, general practitioner and clinical research fellow, Derek \\ G Cook, professor of epidemiology
}

Division of Population Health

Sciences and Education, St

George's, University of London, London SW17 ORE, UK

Correspondence to: S M Shah

sushah@sgul.ac.uk

Cite this as: $B M J$ 2011;342:d912 doi:10.1136/bmj.d912

\section{ABSTRACT}

Objective To describe the quality of care for chronic diseases among older people in care homes (nursing and residential) compared with the community in a pay for performance system.

Design Retrospective analysis of The Health Improvement Network (THIN), a large primary care database.

Setting 326 English and Welsh general practices, 2008-9.

Participants 10387 residents of care homes and 403259 residents in the community aged 65 to 104 and registered for 90 or more days with their general practitioner.

Main outcome measure 16 process quality indicators for chronic disease management appropriate for vulnerable older people for conditions included in the UK Quality and Outcomes Framework.

Results After adjustment for age, sex, dementia, and length of registration, attainment of quality indicators was significantly lower for residents of care homes than for those in the community for 14 of 16 indicators. The largest differences were for prescribing in heart disease $(\beta$ blockers in coronary heart disease, relative risk 0.70, 95\% confidence interval 0.65 to 0.75 ) and monitoring of diabetes (retinal screening, $0.75,0.71$ to 0.80 ). Monitoring hypothyroidism $(0.93,0.90$ to 0.95$)$, blood pressure in people with stroke $(0.92,0.90$ to 0.95$)$, and electrolytes for those receiving loop diuretics $(0.89,0.87$ to 0.92 ) showed smaller differences. Attainment was lower in nursing homes than in residential homes. Residents of care homes were more likely to be identified by their doctor as unsuitable or non-consenting for all Quality and Outcomes Framework indicators for a condition allowing their exclusion from targets; $33.7 \%$ for stroke and $34.5 \%$ for diabetes.

Conclusion There is scope for improving the management of chronic diseases in care homes, but high attainment of some indicators shows that pay for performance systems do not invariably disadvantage residents of care homes compared with those living in the community. High use of exception reporting may compromise care for vulnerable patient groups. The Quality and Outcomes Framework, and other pay for performance systems, should monitor attainment and exception reporting in vulnerable populations such as residents of care homes and consider measures that deal with the specific needs of older people.

\section{INTRODUCTION}

In 2004 the United Kingdom introduced a pay for performance contract for primary care, the Quality and Outcomes Framework. This incentive programme includes several detailed evidence based clinical indicators for the management of chronic disease, and performance on these indicators to specified thresholds triggers additional payments to practices. Such payments account for about a quarter of the income for primary care practices. Introduction of the scheme led to initial improvement and high levels of attainment for included quality indicators. ${ }^{1}$ The scheme allows doctors to identify patients who are not appropriate for, or refuse, an intervention and therefore failure to achieve standards for these patients does not impact on remuneration. Evidence does not suggest widespread inappropriate use of exception reporting. ${ }^{2}$

An international concern is that older people do not receive appropriate management of chronic diseases despite specific interventions being effective in this population. ${ }^{3}$ Care for chronic diseases in nursing and residential homes is provided by general (family) practices and incentivised by the Quality and Outcomes Framework on the same basis as people living in the community. Studies on older people in nursing and residential homes are limited, with few studies allowing explicit comparison with community dwelling residents in large samples. ${ }^{4-8}$ Furthermore, older residents of care homes are not routinely identified or monitored in UK primary care systems or in the Quality and Outcomes Framework. This means that information on whether vulnerable older people in care homes benefit from the UK pay for performance system is lacking.

We examined the quality of care for chronic physical diseases among older people in care homes and the community, focusing on process measures that have been identified as appropriate for vulnerable older 
people for disease areas that are incentivised by the Quality and Outcomes Framework. ${ }^{910}$ Specifically, we tested the hypotheses that in a pay for performance system, quality of chronic disease care is poorer in care homes and that residents of care homes are more likely to be excluded, for payment purposes, from quality targets.

\section{METHODS}

The Health Improvement Network (THIN) is an established primary care database that collects anonymised data from a volunteer sample of UK general practices using the Vision primary care computer system. The database includes a full record of patient registration, consultation, diagnoses, and prescribing for all patients from participating practices. ${ }^{11}{ }^{12} \mathrm{~A}$ feature of The Health Improvement Network database is the family number, which allows practices to link patients who live in the same household or institution.

Of 349 English and Welsh practices providing data to The Health Improvement Network between March 2008 and February 2009, we excluded 19 where, for technical reasons, less than $80 \%$ of patients had successful postcode linkage and four that could not provide complete data over the past two years. Our initial sample included 435568 patients aged 65 and over in 326 practices.

\section{Identifying residents in care homes}

Care homes in the United Kingdom are classified as either nursing homes, providing 24 hour nursing care in addition to assistance with activities of daily living, or residential homes, providing help with activities of daily living but not required to provide care by registered nurses. Residential homes are the equivalent to settings referred to as assisted living facilities in other countries. Care homes do not include older people's residential communities or supported housing projects. Residential and nursing homes in the United Kingdom are registered and regulated by national regulatory organisations. Based on address lists obtained from the regulatory bodies, we commissioned anonymised postcode linkage to identify people who lived in postcodes that included a nursing or residential home.

We identified residents of care homes on the basis of the presence of either a specific record of residence in a care home or at least two other independent markers of residence in a care home: registered address in a care home postcode, a family number with four or more older people in a household, or a record of consultation in a care home. This approach identified 11547 residents in care homes aged 65 and over. We identified $4403(38.1 \%)$ residents directly through a specific Read code for care home residence in their clinical record and a further $7144(61.9 \%)$ through the independent markers. We have previously shown that patients identified through markers are demographically similar to those identified with specific Read codes and that our enhanced detection identifies about $70 \%$ of residents in care home. ${ }^{13}$ Of these residents 10985 were in generalist care homes for older people and the remaining 562 were resident in specialist care homes for alcohol related problems, learning disabilities, and mental health problems.

A further 405107 patients with no care home markers or shared household identifier with patients with care home markers, were identified as resident in the community. We excluded 18914 people whose residential status was uncertain, as their record either included one marker of care home residence or postcode linkage data were not available or they lived with two other older people. This ensured that the community comparison group did not include residents in care homes. Most of these excluded people were not resident in care homes but simply lived in postcodes with a care home.

\section{Participants}

For this analysis we included residents in non-specialist care homes and community dwelling people aged 65 to 104 who were registered for at least 90 days with their general practitioner; 10387 residents in care homes for older people and 403259 older people in the community.

We identified care home type through postcode linkage, which distinguished whether the care home in the postcode was a nursing home or residential home. Some residents in care homes were not classifiable $(\mathrm{n}=1403)$ as they were identified without postcode linkage or their postcode contained both residential and nursing homes.

\section{Approach to identifying quality indicators}

We identified Quality and Outcomes Framework process quality measures for coronary heart disease, stroke, atrial fibrillation, and diabetes, which had equivalent measures in the Rand Institute Assessing Care of Vulnerable Elders (ACOVE-3) quality indicators (see web extra appendix). ${ }^{9}$ These quality indicators were specifically developed by consensus methods as suitable for vulnerable older people, and a subset of Assessing Care of Vulnerable Elders quality indicators are further identified as suitable for patients with advanced dementia and poor prognosis. ${ }^{14}$ This approach ensured that the Quality and Outcomes Framework indicators included in our study were appropriate and suitable for older people in care homes. We also included Quality and Outcomes Framework measures on monitoring of hypothyroidism and blood pressure in chronic disease and Assessing Care of Vulnerable Elders quality indicators on monitoring electrolytes.

\section{Exception reporting in the Quality and Outcomes Framework}

Exception reporting is a mechanism that allows practices to exclude patients from quality standards in the Quality and Outcomes Framework. ${ }^{15}$ Patients may be exception reported as inappropriate or refusing review for a whole disease area such as coronary heart disease 


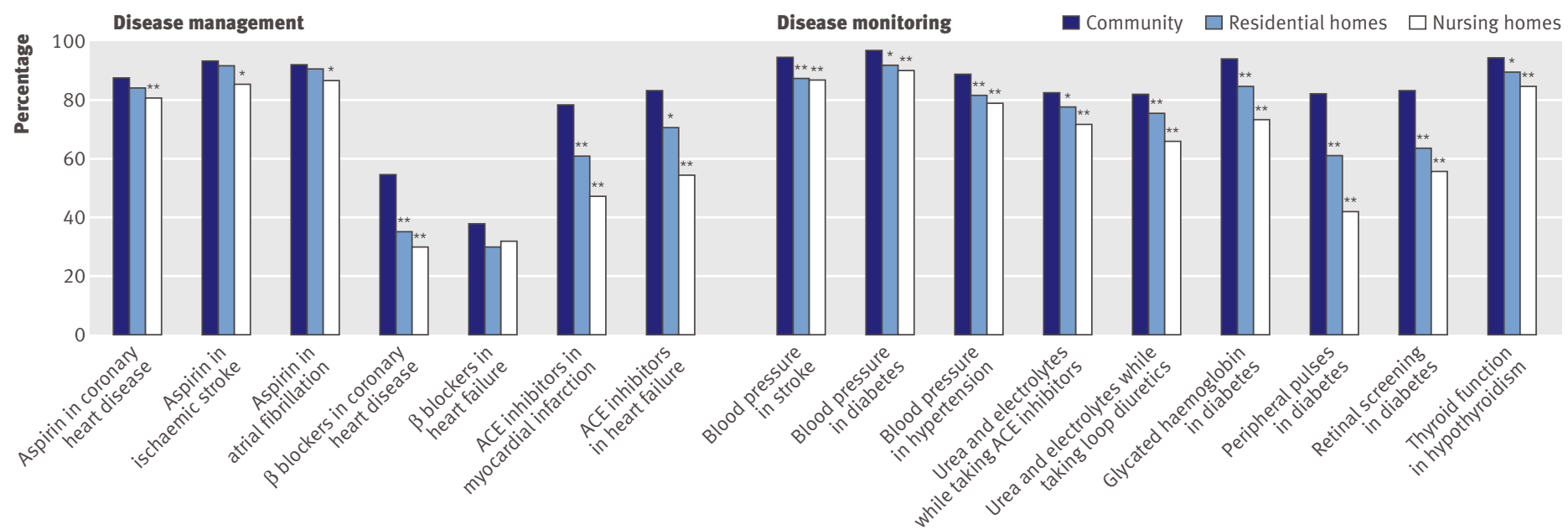

$\mathrm{ACE}=$ angiotensin converting enzyme; ${ }^{\star} \mathrm{P}<0.05,{ }^{\star \star} \mathrm{P}<0.001$ for comparison with community patients. $\mathrm{P}$ values adjusted for age, sex, dementia, and length of registration

Age and sex standardised attainment of quality indicators in the community, residential homes, and nursing homes

(disease wide exceptions); as contraindicated for a specific intervention-for example, as a result of aspirin intolerance; and where a service is not available or a specific intervention refused. In addition, patients are excluded for definitional reasons from indicators if they are, for example, newly registered or have a new diagnosis.

\section{Approach to measuring quality indicators}

For calculating indicator achievement for this study, we excluded patients exception reported as a result of contraindication for a specific intervention or unavailability of a service or refusal of a specific intervention, and patients who did not meet the definitional requirements for an indicator, but we did not exclude patients exception reported as inappropriate or refusing review for a disease area (disease wide exceptions). For indicators not included in the Quality and Outcomes Framework, we developed definitions in line with the approach taken in the framework.

We also undertook analysis excluding all patients with exceptions, including disease wide exceptions, and, for comparability with nationally published attainment in the Quality and Outcomes Framework, we calculated attainment using the remuneration rules of the framework, which exclude or except patients only if they fail to meet the quality standard. We also report separately the proportion of patients in each disease group who were identified with disease wide exceptions.

\section{Statistical analysis}

Achievement of quality indicators was directly age and sex standardised in five year age bands to the combined nursing and residential care home population, with confidence intervals calculated taking account of practice clustering using robust variance estimates. Indicators are shown for all residents in care homes and separately for residents without a recorded diagnosis of dementia. We repeated analyses excluding patients with less than
15 months' registration with their general practitioner to exclude those with poor life expectancy (data not shown). Adjusted analysis was undertaken using a log binomial generalised estimating equation model, which included age (in five year age bands entered as categories), sex, dementia diagnosis, and length of registration $(>15$ months or $<15$ months). Risk ratios and $95 \%$ confidence intervals for these models are presented for comparisons between residents in care homes and those in the community. ${ }^{16}$ Practice effects were included in this model, assuming an exchangeable correlation structure.

\section{RESULTS}

Table 1 shows the characteristics of the residents in care homes and the community.

\section{Disease management}

After adjustment for age and sex, use of antiplatelet therapy or anticoagulation by patients with heart disease, stroke, or atrial fibrillation was slightly lower in nursing and residential homes than in the community. For example, $87.6 \%$ of residents in the community received antiplatelet therapy for coronary heart disease compared with $83.6 \%$ in care homes. Prescribing of angiotensin converting enzyme inhibitors and $\beta$ blockers was noticeably lower for residents with heart disease in care homes $(54.7 \% v 34.4 \%$ for $\beta$ blockers, $78.4 \% v 55.5 \%$ for angiotensin converting enzyme inhibitors). Use of angiotensin converting enzyme inhibitors was also lower in residents in care homes with heart failure (figure and table 2).

\section{Disease monitoring}

Residents in care homes with diabetes were less likely to have a record of glycated haemoglobin being measured and much less likely to have a record of retinal screening or peripheral pulses being assessed compared with community dwelling residents $(94.3 \% v$ $79.4 \%$ for glycated haemoglobin, $82.3 \%$ v 52.4\% for 
Table 1|Characteristics of community dwelling residents and those in care homes aged 65 to 104 with at least 90 days' registration with a general practice $(n=413646)$. Values are numbers (standardised percentages*) unless stated otherwise

\begin{tabular}{|c|c|c|c|c|}
\hline Characteristics & Community & All care homes & Residential homes & Nursing homes \\
\hline No (\%) of patients & $403259(100)$ & $10387(100)$ & $4715(100)$ & $4269(100)$ \\
\hline Mean age (years) & 74.7 & 85.5 & 86.1 & 84.9 \\
\hline No (crude \%) of men & $180658(44.8)$ & $2405(23.2)$ & $975(20.7)$ & $1103(25.8)$ \\
\hline No (crude \%) registered for 15 months & 394677 (97.9) & $8373(80.6)$ & $3881(82.3)$ & $3296(77.2)$ \\
\hline \multicolumn{5}{|l|}{ Patient groups†: } \\
\hline Coronary heart disease & $68843(20.2)$ & 1980 (19.1) & 904 (19.2) & $787(18.4)$ \\
\hline Myocardial infarctł & $8513(2.5)$ & $314(3.0)$ & $147(3.1)$ & $121(2.9)$ \\
\hline Heart failure with left ventricular dysfunction & $8637(3.8)$ & $368(3.5)$ & $188(3.9)$ & $125(2.9)$ \\
\hline Stroke or transient ischaemic attack & $17650(6.3)$ & 1854 (17.9) & $694(15.0)$ & 907 (21.1) \\
\hline Ischaemic stroke & 9308 (3.3) & $1073(10.3)$ & $387(8.4)$ & $547(12.7)$ \\
\hline Atrial fibrillation & 29710 (12.1.) & 1396 (13.4) & 594 (12.4) & 587 (13.8) \\
\hline Diabetes & 52331 (11.2) & 1397 (13.5) & $612(13.5)$ & $578(13.3)$ \\
\hline Hypothyroidism & $34165(11.0)$ & $1246(12.0)$ & $600(12.4)$ & $485(11.6)$ \\
\hline Hypertension & $196631(56.1)$ & $4446(42.8)$ & 2065 (43.5) & $1726(40.6)$ \\
\hline $\begin{array}{l}\text { Taking angiotensin converting enzyme } \\
\text { inhibitors§ }\end{array}$ & $149100(38.3)$ & $2417(23.3)$ & $1143(24.5)$ & 889 (20.7) \\
\hline Taking loop diuretics§ & $41122(19.5)$ & $2874(27.6)$ & 1439 (30.1) & $1083(25.6)$ \\
\hline Dementia & $6450(3.7)$ & $4256(41.0)$ & 1892 (40.1) & 1870 (43.6) \\
\hline \multicolumn{5}{|c|}{$\begin{array}{l}\text { *Directly age and sex standardised to combined care home population. } \\
\text { †Patient groups are based on Quality and Outcomes Framework definitions for calculation of attainment of quality standards and are not necessarily } \\
\text { disease prevalence. } \\
\text { †Since } 1 \text { April } 2003 \text {. } \\
\text { §Based on prescription in past six months. }\end{array}$} \\
\hline
\end{tabular}

peripheral pulses, $83.3 \%$ v $59.8 \%$ for retinal screening). Residents in care homes taking angiotensin converting enzyme inhibitors or loop diuretics were less likely to have their electrolytes monitored in the past year $(81.9 \%$ v $71.6 \%$ for loop diuretics) and residents treated for hypothyroidism were less likely to have had thyroid function tests. Blood pressure was slightly less likely to be recorded in the past year in residents in care homes with stroke, diabetes, or hypertension (figure and table 2).

Effect of dementia, length of registration, and type of care home

Residents in care homes without dementia were more likely to achieve the quality indicators, but the differences between care homes and the community persisted after exclusion of residents with dementia (table 2). Restricting analysis to people with at least 15 months' registration with their general practitioner made little difference to either the absolute value or the difference between settings.

After adjustment for age, sex, dementia, length of registration, and practice, attainment of quality indicators was significantly lower $(\mathrm{P}<0.002)$ in care homes for all indicators except use of $\beta$ blockers in heart failure and use of aspirin or anticoagulation in atrial fibrillation (table 2). The adjusted risk ratios for receipt of $\beta$ blockers in coronary heart disease was 0.70 (95\% confidence interval 0.65 to 0.75$)$, for retinal screening in diabetes was 0.75 (0.71 to 0.80 ), for monitoring of thyroid function in hypothyroidism was 0.93 (0.90 to 0.95 ), and for monitoring of electrolytes in residents taking loop diuretics was 0.89 (0.87 to 0.92 ).
For residential homes alone, 12 of 16 indicators were significantly lower than those for the community and for nursing homes alone 15 indicators were significantly lower (figure). Overall, after adjustment, aside from use of $\beta$ blockers in heart failure, all quality indicators were less likely to be achieved in nursing homes than in residential homes (figure).

\section{Exception reporting}

Table 3 shows the proportion of patients identified as either unsuitable or dissenting from all indicators for each condition. Disease wide exception rates increased in the community with age. After standardisation for age and sex, the proportion of residents with disease wide exceptions was noticeably higher in care homes for all conditions, with $33.7 \%$ of residents in care homes with stroke excepted from calculation of Quality and Outcomes Framework target payments compared with $16.9 \%$ in the community, and $34.5 \%$ compared with $9.2 \%$ for diabetes (table 3 ). This difference persisted after exclusion of people with a dementia diagnosis and limiting analysis to residents with a minimum of 15 months' registration. Exception reporting was much higher in nursing homes than in residential homes.

The effect of exception reporting on attainment of quality indicators and differences between care homes and the community was examined by excluding all excepted patients from calculation of the relevant quality indicators. After these exclusions, the differences between care home and community dwelling residents remained statistically significant for all indicators except use of anticoagulation in atrial fibrillation and $\beta$ blockers in heart failure. 
Table 2 |Attainment of quality indicators in community dwelling residents and those in care homes

\begin{tabular}{|c|c|c|c|c|c|c|c|c|}
\hline \multirow[b]{3}{*}{$\begin{array}{l}\text { Intervention: patient } \\
\text { group }\end{array}$} & \multirow[b]{3}{*}{ Source } & \multirow{2}{*}{\multicolumn{2}{|c|}{ Community }} & \multirow{3}{*}{$\begin{array}{c}\text { All care homes } \\
\text { Standardised \%* } \\
(95 \% \mathrm{Cl})\end{array}$} & \multirow{3}{*}{$\begin{array}{c}\text { All care } \\
\text { homes, no } \\
\text { dementia }\end{array}$} & \multirow{3}{*}{$\begin{array}{c}\text { Care home } v \\
\text { community } \\
\text { Adjusted risk ratio† }(95 \% \\
\mathrm{Cl})\end{array}$} & \multicolumn{2}{|c|}{ Appropriate } \\
\hline & & & & & & & \multirow[b]{2}{*}{$\begin{array}{l}\text { Advanced } \\
\text { dementia }\end{array}$} & \multirow[b]{2}{*}{$\begin{array}{l}\text { Poor } \\
\text { prognosis }\end{array}$} \\
\hline & & $\begin{array}{l}\text { Crude \% } \\
(95 \% \mathrm{Cl})\end{array}$ & $\begin{array}{l}\text { Standardised \%* } \\
(95 \% \mathrm{Cl})\end{array}$ & & & & & \\
\hline \multicolumn{9}{|l|}{ Disease management } \\
\hline \multicolumn{9}{|l|}{ Aspirin or anticoagulants: } \\
\hline Coronary heart disease & QOF/ACOVE & 91.7 (91.3 to 92.1) & $87.6(86.8$ to 88.4$)$ & 83.6 (81.5 to 85.8$)$ & 84.7 (82.2 to 87.1$)$ & 0.96 (0.94 to 0.99) & Yes & No \\
\hline Ischaemic stroke & QOF/ACOVE & 95.2 (94.7 to 95.7) & 93.5 (92.3 to 94.8$)$ & 88.3 (85.6 to 91.0$)$ & 90.1 (87.3 to 92.9) & $0.96(0.93$ to 0.98$)$ & Yes & Yes \\
\hline Atrial fibrillation & QOF/ACOVE & 93.9 (93.4 to 94.3$)$ & $92.3(91.6$ to 93.1$)$ & 88.3 (86.2 to 90.3$)$ & 89.1 (86.9 to 91.4) & $0.98(0.96$ to 1.00$)$ & Yes & Yes \\
\hline \multicolumn{9}{|l|}{$\beta$ blockers: } \\
\hline Coronary heart disease & QOF/ACOVE & $62.8(61.8$ to 63.7$)$ & 54.7 (53.4 to 56.0$)$ & 34.4 (32.1 to 36.8$)$ & 39.2 (36.0 to 42.4) & $0.70(0.65$ to 0.75$)$ & Yes & No \\
\hline Heart failure & QOF/ACOVE & $50.3(48.3$ to 52.4$)$ & 37.8 (35.2 to 40.5$)$ & 34.4 (25.9 to 42.9) & $36.0(25.9$ to 46.1$)$ & $0.93(0.72$ to 1.18$)$ & No & No \\
\hline \multicolumn{9}{|l|}{$\begin{array}{l}\text { Angiotensin converting } \\
\text { enzyme inhibitors: }\end{array}$} \\
\hline Myocardial infarction & QOF/ACOVE & 85.5 (84.6 to 86.4$)$ & 78.4 (76.1 to 80.8$)$ & 55.5 (50.4 to 60.6$)$ & $61.4(55.3$ to 67.5$)$ & $0.76(0.68$ to 0.84$)$ & Yes & No \\
\hline Heart failure & QOF/ACOVE & 88.3 (87.5 to 89.2 ) & $83.2(81.4$ to 85.0$)$ & 67.5 (62.1 to 72.9$)$ & 70.4 (64.3 to 76.4$)$ & $0.82(0.75$ to 0.90$)$ & No & No \\
\hline \multicolumn{9}{|l|}{ Disease monitoring } \\
\hline \multicolumn{9}{|l|}{ Blood pressure: } \\
\hline Stroke & QOF & 95.9 (95.5 to 96.3$)$ & 94.8 (94.0 to 95.6$)$ & 87.4 (85.1 to 89.8$)$ & 88.1 (85.7 to 90.5$)$ & 0.92 (0.90 to 0.95$)$ & - & - \\
\hline Diabetes & QOF/ACOVE & 98.1 (97.9 to 98.4$)$ & 97.1 (96.4 to 97.8$)$ & $91.9(89.7$ to 94.0$)$ & 93.3 (91.0 to 95.7$)$ & 0.95 (0.93 to 0.97$)$ & No & No \\
\hline Hypertension & QOF & 91.0 (90.5 to 91.6) & 88.9 (88.1 to 89.6$)$ & 80.7 (78.3 to 83.0) & 81.2 (78.6 to 83.7) & $0.91(0.89$ to 0.94$)$ & - & - \\
\hline \multicolumn{9}{|l|}{ Urea and electrolytes: } \\
\hline $\begin{array}{l}\text { Taking angiotensin } \\
\text { converting enzyme } \\
\text { inhibitor }\end{array}$ & ACOVE & 85.4 (84.4 to 86.3$)$ & 82.6 (81.4 to 83.7$)$ & 75.4 (72.9 to 77.9$)$ & $76.0(73.2$ to 78.7$)$ & 0.91 (0.89 to 0.94$)$ & Yes & Yes \\
\hline Taking loop diuretic & ACOVE & 84.9 (84.1 to 85.8$)$ & $81.9(80.7$ to 83.0$)$ & $71.6(69.1$ to 74.1$)$ & 73.4 (70.5 to 76.3$)$ & $0.89(0.87$ to 0.92$)$ & Yes & Yes \\
\hline \multicolumn{9}{|l|}{ Glycated haemoglobin: } \\
\hline Diabetes & QOF/ACOVE & 96.5 (96.2 to 96.8$)$ & 94.3 (93.5 to 95.2) & 79.4 (76.1 to 82.7$)$ & 82.9 (79.3 to 86.5$)$ & $0.87(0.83$ to 0.90$)$ & No & No \\
\hline \multicolumn{9}{|l|}{ Peripheral pulses: } \\
\hline Diabetes & QOF/ACOVE & 88.4 (87.4 to 89.3$)$ & $82.3(80.7$ to 83.8$)$ & $52.4(47.9$ to 57.0$)$ & $58.0(53.1$ to 62.8$)$ & $0.66(0.61$ to 0.72$)$ & No & No \\
\hline \multicolumn{9}{|l|}{ Retinal screening: } \\
\hline Diabetes & QOF/ACOVE & 88.8 (87.6 to 90.1$)$ & $83.3(81.5$ to 85.1$)$ & 59.8 (55.7 to 63.9) & 64.4 (59.9 to 69.0$)$ & $0.75(0.71$ to 0.80$)$ & No & No \\
\hline \multicolumn{9}{|l|}{ Thyroid function tests: } \\
\hline Hypothyroidism & QOF & 96.4 (96.0 to 96.9) & 94.8 (94.0 to 95.6$)$ & 87.7 (85.2 to 90.3$)$ & 87.8 (84.8 to 90.9$)$ & 0.93 (0.90 to 0.95$)$ & - & - \\
\hline
\end{tabular}

The effect of disease wide exception reporting on remunerable attainment was also examined. The application of Quality and Outcomes Framework exception rules allowed practices to obtain much higher remunerable attainment in care homes. For example, crude uptake of retinal screening in diabetes rose from $60.5 \%$ to $76.6 \%$ and use of $\beta$ blockers in heart disease from $33.7 \%$ to $45.9 \%$.

Attainment of quality indicators in the community in the study sample, calculated using the remuneration rules of the Quality and Outcomes Framework, showed good agreement with nationally published Quality and Outcomes Framework attainment.

\section{DISCUSSION}

Achievement of 14 of the 16 quality indicators was lower for residents in care homes than for those in the community, with the most noticeable differences for residents of nursing homes, prescribing in patients with heart disease, and physical monitoring of people with diabetes. Quality indicators for use of antiplatelet therapy and monitoring of blood pressure showed the least difference between settings. Doctors were more likely to exclude residents in care homes from Quality and Outcomes Framework monitoring. Differences between settings were not explained by higher prevalence of dementia in care homes, patients with limited life expectancy, or exception reporting of patients.

Strengths and limitations of the study

This is the first study to examine quality of care for residents in care homes since the introduction of pay for performance in the primary care contract. Our study deals with key limitations of existing international studies in care homes, which are either regionally based or do not include a community based comparison. Quality and Outcomes Framework equivalent achievement in our community population was close to national published attainment data, which supports the representativeness of our findings. 
Table 3|Disease wide exceptions from Quality and Outcomes Framework targets in community dwelling residents and those in care homes

\begin{tabular}{|c|c|c|c|c|c|c|}
\hline \multirow[b]{2}{*}{ Disease wide exception* } & \multicolumn{2}{|c|}{ Community } & \multirow{2}{*}{$\begin{array}{c}\text { All care homes } \\
\text { Standardised \%† } \\
(95 \% \mathrm{Cl})\end{array}$} & \multirow{2}{*}{$\begin{array}{c}\text { All care homes } \\
\text { without dementia } \\
\begin{array}{c}\text { Standardised \%† } \\
(95 \% \mathrm{Cl})\end{array}\end{array}$} & \multirow{2}{*}{$\begin{array}{c}\text { Residential homes } \\
\text { Standardised \%† } \\
(95 \% \mathrm{Cl})\end{array}$} & \multirow{2}{*}{$\begin{array}{c}\text { Nursing homes } \\
\text { Standardised \%† } \\
(95 \% \mathrm{Cl})\end{array}$} \\
\hline & $\begin{array}{l}\text { Crude \% } \\
(95 \% \mathrm{Cl})\end{array}$ & $\begin{array}{c}\text { Standardised \%† } \\
\quad(95 \% \mathrm{Cl})\end{array}$ & & & & \\
\hline Coronary heart disease & $4.4(3.8$ to 5.0$)$ & 10.3 (8.8 to 11.7 ) & 29.3 (25.0. to 33.7 ) & 23.3 (19.4 to 27.2 ) & 26.3 (21.0 to 31.6$)$ & 34.5 (28.5 to 40.5$)$ \\
\hline Heart failure & 2.4 (1.9 to 2.9$)$ & $4.6(3.4$ to 5.8$)$ & 18.8 (13.6 to 24.0$)$ & 17.5 (11.7 to 23.2$)$ & 14.8 (8.0 to 21.6$)$ & 26.3 (16.3 to 36.2 ) \\
\hline Stroke & 8.6 (7.4 to 9.7$)$ & 16.9 (14.7 to 19.2$)$ & 33.7 (29.0 to 38.3$)$ & 28.9 (24.3 to 33.4$)$ & 30.7 (24.8 to 36.6$)$ & 35.8 (29.9 to 41.7$)$ \\
\hline Atrial fibrillation & $1.1(0.9$ to 1.4$)$ & 2.2 (1.7 to 2.7$)$ & $5.6(3.7$ to 7.4$)$ & $5.0(3.0$ to 7.0$)$ & $3.8(2.1$ to 5.4$)$ & 6.8 (3.9 to 9.8$)$ \\
\hline Diabetes & $4.8(4.2$ to 5.3$)$ & 9.2 (7.9 to 10.6$)$ & 34.5 (29.6 to 39.4$)$ & 28.4 (23.5 to 33.2$)$ & 27.1 (21.5 to 32.7$)$ & 42.9 (35.9 to 49.9$)$ \\
\hline Hypothyroidism & 0.5 (0.4 to 0.7$)$ & $0.9(0.5$ to 1.2$)$ & 4.7 (3.1 to 6.4$)$ & $4.4(2.6$ to 6.1$)$ & $4.1(1.6$ to 6.5$)$ & $4.4(2.2$ to 6.6$)$ \\
\hline Hypertension & $2.0(1.7$ to 2.3$)$ & 4.1 (3.4 to 4.8 ) & $7.9(6.2$ to 9.5$)$ & $6.7(5.1$ to 8.2$)$ & 6.8 (4.8 to 8.8$)$ & 8.4 (5.7 to 11.1$)$ \\
\hline
\end{tabular}

An important problem with comparisons between residents in care homes and those in the community is the adequacy of adjustment for important demographic and clinical differences between the populations. We adjusted all analyses for age and sex and also present analysis stratified by dementia, but cannot completely exclude the effects of residual or unmeasured confounding in our comparisons. However, examination of attainment stratified by age, sex, and dementia confirmed the lower attainment in care homes.

Our data rely on quality of recording in the electronic primary care record. As primary care computer systems are used for repeat prescribing and laboratory results are transmitted electronically to practices, these aspects of care are likely to be fully and accurately recorded. However, measures that require recording at the time of consultation-for example, blood pressure - may be less likely to be recorded in care homes where contemporaneous access to practice computer systems may not always be possible.

\section{Appropriateness of quality indicators}

Not all interventions for chronic disease are appropriate for all older people, and comorbidity and life expectancy need to be considered. ${ }^{14}$ We addressed this concern by separately analysing patients without recorded dementia and restricting analysis to patients with at least 15 months' registration with their general practice; thus excluding patients with limited life expectancy. Neither analysis gave substantially different findings. In addition, poorer attainment in care homes persisted after exclusion of patients with any doctor recorded exception and was seen for measures considered appropriate for patients with advanced dementia and poor prognosis (table 2).

The Quality and Outcomes Framework does not include problems that are particular concerns in care homes, such as nutrition, mobility, continence, pressure ulcers, and pain. ${ }^{17}$ Although quality indicators for these conditions are available in the Assessing Care of Vulnerable Elders quality indicators, they cannot currently be measured meaningfully using primary care data in the United Kingdom. Therefore Quality and Outcomes Framework based indicators cannot capture fully the quality of clinical care in care homes. Nevertheless, good management of conditions such as stroke and diabetes is important for all older people, irrespective of residential setting. For example, diabetes in nursing homes is associated with poor outcomes, including hospital admission and pressure ulcers. $^{18}$

\section{Comparison with previous studies}

Existing studies of quality of chronic disease care in UK care homes are sparse. A small study in four nursing homes in 2003, before introduction of the new primary care contract, identified low attainment of several of the indicators in our study. ${ }^{4}$ Internationally, studies have reported poor quality of care in nursing homes for diabetes, heart failure, and stroke but usually do not include a community comparison group..$^{5-8} \mathrm{~A}$ recently reported large US study measured attainment of selected Assessing Care of Vulnerable Elders quality indicators in nursing homes in 2000 and found lower attainment than in our study in a population with a higher prevalence of dementia, despite taking account of potential contraindications. ${ }^{6}$ Our better performance than this US study, except for monitoring of electrolytes, may reflect both the effect of incentives in the Quality and Outcomes Framework and also improvement over time. A recent large Belgian study on prescribing in nursing homes, without a community comparison group, has reported higher prescribing of $\beta$ blockers and angiotensin converting enzyme inhibitors in heart disease. ${ }^{19}$

A national study of exception reporting in the Quality and Outcomes Framework found low levels of overall exception reporting for process measures and did not suggest widespread inappropriate overuse but was not able to assess the experience of vulnerable population subgroups. ${ }^{2}$ Our findings suggest that low overall exception rates may mask high exception rates for patient groups that make up a small proportion of the population.

The similarity of $\beta$ blocker prescribing for heart failure in care home and community residents is unexpected as we have recently shown age and socioeconomic inequity for this intervention. ${ }^{20}$ This new Quality and Outcomes Framework indicator, in 


\section{WHAT IS ALREADY KNOWN ON THIS TOPIC}

The UK primary care pay for performance system, the Quality and Outcomes Framework (QOF), has improved quality of chronic disease care for included conditions, but not necessarily for others

Older people do not always receive the same quality of chronic disease care as younger patients

Information on chronic disease care in nursing and residential homes compared with the community is limited and it is not known whether older residents in care homes have benefited from implementation of QOF, as there is no separate monitoring of this vulnerable group

\section{WHAT THIS STUDY ADDS}

Chronic disease care for conditions included in QOF, measured by indicators suitable for vulnerable older people, is poorer for residents in care homes than for those in the community, even after taking account of differences in dementia prevalence and life expectancy

Practitioners are much more likely to identify patients in care homes as unsuitable or nonconsenting for all QOF indicators for a condition, allowing their exclusion from payment targets, and the pattern of exclusion suggests that these decisions are not always individualised

QOF does not separately identify or include measures focused on the needs of vulnerable older people, limiting its value for quality improvement or monitoring of care for this group

2006, has low uptake in the community and this suggests that differences between care homes and the community may only emerge when an intervention has high uptake, as is the case for the other indicators examined.

\section{Implications}

Our study shows a need to improve care for chronic diseases among older people in care homes, but the absence of large differences for some Quality and Outcomes Framework indicators gives reassurance that pay for performance systems do not invariably disadvantage vulnerable groups. It is notable that the only indicator lower than the US study in nursing homes was monitoring of electrolytes, which is not included in the Quality and Outcomes Framework.

For some interventions, lower attainment of quality indicators may be appropriate as a result of comorbidity and poor life expectancy. ${ }^{14}$ Most indicators in the Quality and Outcomes Framework aim to ensure that patients receive evidence based interventions for common chronic conditions, with a strong emphasis on improving life expectancy and reducing long term complications. These objectives may be less important for older people in care homes than more immediate concerns, leading to a perception by clinicians that the Quality and Outcomes Framework is not relevant to residents in care homes, with resultant high disease wide exception rates. However, such decisions need to be explicit, individualised, and consensual and not based on assumptions about capacity to benefit. High disease wide exceptions suggest a less individualised approach and may act as a disincentive to good disease management.

Notably, the disease wide exceptions mean that patients are labelled as either unsuitable or non- consenting from indicators that are achieved. For example, although $43 \%$ of patients in nursing homes were excepted from diabetes management, $73 \%$ were reported to have been tested for glycated haemoglobin. Our findings highlight a risk for pay for performance systems that care for small, vulnerable, and hard to monitor groups may be compromised by inappropriate or blanket use of exception reporting.

The lower attainment on measures that require access to blood tests and for diabetic care may reflect difficulties in accessing services in care homes rather than physician behaviour. Such inequity may be an unintended consequence of improvements in the organisation of care that are encouraged by pay for performance systems. In the United Kingdom, there has been a move to systematic diabetic care with specialist practice based clinics and centralised diabetic retinal screening, but these benefits may not reach residents in care homes who are not able to attend the clinic. ${ }^{21} \mathrm{~A}$ need exists to ensure equity of access for residents in care homes, and other vulnerable groups, to new service models incentivised in pay for performance systems.

A weakness of the Quality and Outcomes Framework is the absence of indicators for problems with particular relevance to people in care homes such as pain management or continence care. Inclusion of such measures in the framework may be problematic for several reasons, including ease of recording or extraction from primary care systems, and difficulty with precise diagnosis, and the framework may not necessarily be an appropriate vehicle for such quality improvement. ${ }^{22}$ However, the absence of relevant indicators means that pay for performance incentives do not encourage recording or reward important aspects of care for vulnerable older people. Evidence from the United States suggests that quality of care for problems specific to older people is poorer than that for other chronic diseases, and, more specifically, areas not included in the Quality and Outcomes Framework may be relatively neglected in UK primary care. ${ }^{23-25}$ Given that we have shown poorer attainment of Quality and Outcomes Framework measures in care homes, it is likely that quality of care for non-incentivised problems is worse. We have previously advocated the separate identification of care home residents in healthcare systems for quality monitoring, and our findings emphasise this recommendation. ${ }^{13}$ Our current findings support enhancement of pay for performance systems to include measures that are particularly relevant to residents of care homes and vulnerable older people in the community, such as those included in the Assessing Care of Vulnerable Elders quality indicators for continence, sensory impairment, chronic pain, and falls.

We thank Richard Hubbard, Sarah Lewis, and other colleagues from the Division of Epidemiology and Public Health, University of Nottingham, for their help and advice on the use of THIN data in developing this project. Contributors: SMS conceived the study and led the project. He is guarantor for the paper. IMC undertook the analysis. All authors 
contributed to the development of the project methodology, interpretation of the results, and drafting of the paper. Funding: This study was funded by a grant from the BUPA Foundation, an independent medical research charity. The funder had no involvement in the study design; collection, analysis, and interpretation of the data; writing of the article; or decision to submit the article for publication. Competing interests: All authors have completed the Unified Competing Interest form at www.icmje.org/coi_disclosure.pdf (available on request from the corresponding author) and declare no support from any organisation for the submitted work; no financial relationships with any organisations that might have an interest in the submitted work in the previous 3 years; no other relationships or activities that could appear to have influenced the submitted work.

Ethical approval: This study was approved by the South-East Multicentre Research Ethics Committee (reference 08/H1102/33).

Data sharing: No additional data available.

1 Doran T, Fullwood C, Gravelle H, Reeves D, Kontopantelis E, Hiroeh U, et al. Pay-for-performance programs in family practices in the United Kingdom. N Engl J Med 2006;355:375-84.

2 Doran T, Fullwood C, Reeves D, Gravelle H, Roland M. Exclusion of patients from pay-for-performance targets by English physicians. $N$ Engl J Med 2008;359:274-84.

3 Rochon P, Gurwitz JH. Prescribing for seniors. Neither too much nor too little. JAMA 1999;282:113-5.

4 Fahey T, Montgomery AA, Barnes J, Protheroe J. Quality of care for elderly residents in nursing homes and elderly people living at home: controlled observational study. BMJ 2003:326:580.

5 Heckman GA, Misiaszek B, Merali F, Turpie ID, Patterson CJ, Flett N, et al. Management of heart failure in Canadian long-term care facilities. Can J Cardiol 2004;20:963-9.

6 Zingmond DS, Saliba D, Wilber KH, MacLean CH, Wenger NS. Measuring the quality of care provided to dually enrolled Medicare and Medicaid beneficiaries living in nursing homes. Med Care 2009; 47:536-44.

7 Feldman SM, Rosen R, DeStasio J. Status of diabetes management in the nursing home setting in 2008: a retrospective chart review and epidemiology study of diabetic nursing home residents and nursing home initiatives in diabetes management. J Am Med Dir Assoc 2009;10:354-60

8 Litaker JR, Chou JY. Patterns of pharmacologic treatment of congestive heart failure in elderly nursing home residents an related issues: a review of the literature. Clin Ther 2003;25:1918-35

9 ACOVE Investigators. Assessing Care of Vulnerable Elders-3 Quality Indicators. / Am Geriatr Soc 2007:55:S464-87.

10 Saliba D, Solomon D, Rubenstein L, Young R, Schnelle J, Roth C, et al. Quality indicators for the management of medical conditions in nursing home residents. J Am Med Dir Assoc 2004;5:297-309.
11 Bourke A, Dattani H, Robinson M. Feasibility study and methodology to create a quality-evaluated database of primary care data. Inform Primary Care 2004;12:171-7.

12 Lewis JD, Schinnar R, Bilker WB, Wang X, Strom BL. Validation studies of the health improvement network (THIN) database for pharmacoepidemiology research. Pharmacoepidemiol Drug Saf 2007;16:393-401.

13 Shah SM, Carey IM, Harris T, DeWilde S, Hubbard R, Lewis S, et al. Identifying the clinical characteristics of older people living in care homes using a novel approach in a primary care database. Age Ageing 2010;39:617-23.

14 Wenger NS, Solomon DH, Amin A, Besdine RK, Blazer DG, Cohen H, et al. Application of Assessing Care of Vulnerable Elders-3 Quality Indicators to patients with advanced dementia and poor prognosis. Am Geriatr Soc 2007;55:S457-63.

15 NHS Employers. Guidance on exception recording. NHS Employers, 2006.

16 Barros Al, Hirakata VN. Alternatives for logistic regression in crosssectional studies: an empirical comparison of models that directly estimate the prevalence ratio. BMC Med Res Methodol 2003;3:21.

17 McMurdo MET, Witham MD. Health and welfare of older people in care homes. BMJ 2007;334:913-4.

18 Resnick HE, Heineman J, Stone R, Shorr RI. Diabetes in US nursing homes, 2004. Diabetes Care 2008;31:287-8.

19 Petrovic M, Cobbaert K, Vander Stichele R. Assessing of medication prescribing quality in Belgian elderly care homes. Br J Clin Pharmaco 2010;69:713.

20 Shah SM, Carey IM, DeWilde S, Richards N, Cook DG. Trends and determinants of beta-blocker prescribing in heart failure. Br J Gen Pract 2008;58:862-9.

21 Shojania KG, Ranji SR, McDonald KM, Grimshaw JM, Sundaram V, Rushakoff RJ, et al. Effects of quality improvement strategies for type 2 diabetes on glycemic control: a meta-regression analysis. JAMA 2006;296:427-40.

22 Lester H, Campbell S. Developing Quality and Outcomes Framework (QOF) indicators and the concept of "QOFability". Qual Prim Care 2010;18:103-9.

23 Wenger NS, Solomon DH, Roth CP, Maclean CH, Saliba D, Kamberg CJ, et al. The quality of medical care provided to vulnerable community-dwelling older patients. Ann Intern Med 2003;139:740-7.

24 Steel N, Maisey S, Clark A, Fleetcroft R, Howe A. Quality of clinical primary care and targeted incentive payments: an observational study. BrJ Gen Pract 2007;57:449-54.

25 Steel N, Bachmann M, Maisey S, Shekelle P, Breeze E, Marmot M, et al. Self reported receipt of care consistent with 32 quality indicators: national population survey of adults aged 50 or more in England. BMJ 2008;337:a957.

Accepted: 29 November 2010 